\title{
Peptide Assisted Imprinting for Turn-On Fluorescence Detection of Proteins ${ }^{+}$
}

\author{
Edmondo Battista ${ }^{1, *}$, Liana P Scognamiglio ${ }^{2}$, Filippo Causa ${ }^{1}$ and Paolo Antonio Netti ${ }^{1,2}$ \\ 1 Interdisciplinary Research Centre on Biomaterials (CRIB), University of Naples "Federico II", P.le Tecchio \\ 80, 80125 Napoli, Italy; causa@unina.it (F.C.); nettipa@unina.it (P.A.N.) \\ 2 CABHC IIT@CRIB, Istituto Italiano di Tecnologia,Largo Barsanti e Matteucci, 8012 Napoli, Italy; \\ pasqualina.scognamiglio@iit.it \\ * Correspondence: edmondo.battista@unina.it \\ + Presented at 7th International Symposium on Sensor Science, Napoli, Italy, 9-11 May 2019.
}

Published: 9 July 2019

Current limitations in protein imprinting technology above all rely on poor cavity control for sensing purpose $[1,2]$.

The aim of this work is to obtain superior chemical control over the imprinted cavity by exploiting the interaction of selected peptides in order to realize new materials with integrated reporting systems. Herein we introduce a novel approach for the protein imprinting based on the introduction of a multifunctionalized peptide in the polymerization phase as reporting and active assistant recognition elements (AAREs) [3]. Such Hybrid Peptide-Polymer Imprinting (HyPPI) envisages a hydrogel matrix where a hybrid material is produced by the co-polymerization between monomers and specific peptides [3].

HyPPI showed low micromolar affinity for the imprinted protein as well as high selectivity. The derivatization of peptides with environment sensitive fluorochrome, such as Dansyl, allowed to reveal the presence of the imprinted protein and with appropriate calibration its concentration. This work represents an advance in the field of self reporting materials that can be integrated directly with optical microdevices and in this way a general tool that would mimick the biologic machinery is provided, through the adaptation of concepts of supramolecular complexes to bulk materials.

\section{References}

1. Ye, L.; Mosbach, K. Molecular imprinting: synthetic materials as substitutes for biological antibodies and receptors. Chem. Mater. 2008, 20, 859-868.

2. Sunayama, H.; Ooya, T.; Takeuchi, T. Fluorescent protein-imprinted polymers capable of signal transduction of specific binding events prepared by a site-directed two-step post-imprinting modification. Chem. Commun. 2014, 50, 1347-1349.

3. Battista, E.; Scognamiglio, P.L.; Luise, N.D.; Raucci, U.; Donati, G.; Rega, N.; Nettiabd, P.A.; Causa, F. Turnon fluorescence detection of protein by molecularly imprinted hydrogels based on supramolecular assembly of peptide multi-functional blocks. J. Mate. Chem. B 2018, 6, 1207-1215.

(C) 2019 by the authors. Licensee MDPI, Basel, Switzerland. This article is an open access article distributed under the terms and conditions of the Creative Commons Attribution (CC BY) license (http://creativecommons.org/licenses/by/4.0/). 